\title{
A CASE OF ASCENDING UNILATERAL PARALYSIS.
}

\author{
By L. NeWMark, M.D.
}

OF SAN FRANCISCO.

When I first saw the patient whose disease I am about to report, I thought the symptoms were caused by a cerebral focal lesion. This was the view taken also by two distinguished German neurologists whom the patient later went abroad to consult. Neither, however, seems to have considered this diagnosis as firmly established. The most salient feature of the clinical picture is the loss of power involving first the lower extremity of one side and then the upper, so that finally a hemiplegia has resulted. Dr. C. K. Mills ${ }^{2}$ published in I900 an account of a case of this kind, which he regarded as representing a new form of degenerative disease. Whatever interest may be excited by the novelty of this disease may, I think, be shared by the following observation:

In November, I900, S. B., a young man, 23 years old, complained that for six months past his left leg had been growing weaker. He would trip often on rough pavements because he could not clear the ground well with the tip of the left foot. At times he could not use the left arm well, so that he occasionally was unable to manipulate his knife and fork properly. Such weakness of the left arm, however, would soon pass off, but he asserted that it might be brought on by exertion. There had been no syphilitic infection. He had been subject to headaches, generally frontal, a few years earlier, but they had become very infrequent. His general health was excellent.

The patient is about 5 feet 6 inches in height and weighs over 200 pounds. In unaffected parts his muscular development is Herculean. His condition from November I 900 to December Igor was as follows: He has walked from the time I first saw him in a manner that suggested a foot-drop on the left side, not with the circumduction of the foot such as is seen in the ordinary hemiplegia of cerebral origin. He was able to perform all move-

\footnotetext{
${ }^{1}$ Read by title at the meeting of the American Neurological Association, June $\mathrm{r}, 2$ and 3,1905 .

"Journal of Nervous and Mental Drs., April, rgoo.
} 
ments in the knee and hip; but with less force than on the right side. Greater was the reduction of. power at the ankle and in the toes: There was marked ankle-drop, dorsal flexion of the foot being very feeble, and except for some ability to extend the big toe the toes were almost completely paralyzed. The knee-jerk and heel-jerk were lively on both sides, but the left were much in excess of the right. At first there was only a brief indication of ankle-clonus on the left side, but by March Igor a lively ankleclonus was easily produced. No plantar reflex at all could be obtained in the left foot at any of the numerous examinations; from the right sole either a faint flexor response was elicited, or only a contraction of the tensor fasciae latae, or, on some occasions, no response at all. The cremasteric and abdominal reflexes were normal. The left lower extremity was flabby, not spastic, and exhibited a general wasting. The circumference of the left leg at a certain point was (in December, IgOI,) $37 \% \frac{1}{2}$, that of the right $391 / 2 \mathrm{~cm}$. The circumference of the left thigh was at the same time to that of the right as $53^{1 / 2}$ to 58 .

The left upper extremity was also clearly thinner than the right. This was especially noticeable when the left contracted biceps was compared with its huge fellow on the other side. This difference between the two upper limbs was observed from the beginning of my acquaintance with the patient. In October, I9oI, where the left forearm measured $24 \frac{1}{2} \mathrm{~cm}$. the right measured $26 \mathrm{I} / 2$. Across the biceps brachii, when the forearm was extended, the left arm measured $293 / 4 \mathrm{~cm}$. to $3 \mathrm{I} 3 / 4$ and across the contracted biceps the circumference of the left arm was $3 \mathrm{I} \mathrm{cm}$. to 34 on the unaffected side. Atrophy was also distinctly shown in the altered curve of the neck on the left and in the rounding of the left shoulder. In November, Igoo, it was noted that the grasp of the left hand was quite good; a year later the power in the left upper extremity was still fair, although less than in the right. But the patient had full use of this limb. It is not recorded that he ever complained of any permanent impairment in it during this period. The supinator and triceps jerks were not at all exaggerated on either side; in fact they were rather feebler than normally, and there was no constant difference in this respect between the two upper extremities.

In the beginning of 1902 the patient went abroad to seek medical advice and returned in June '1903. 
His left arm now hung limp, of no practical use. That is its present condition. The fingers are flexed, the hand is closed, and he is much annoyed by the thumb "always being caught." If the fingers be passively extended he can exert a very fair grip. At the wrist there is great weakness and the flexors have lost even more of their power than the extensors. Flexion of the elbow is feebly performed, but the power of extending it is remarkably well preserved, considering the weakness in the other movements of the upper extremity. The patient can hardly abduct the humerus, the arm dangles at his side. If the arm be passively elevated to the horizontal he cannot raise it higher or even hold it there. By raising the shoulder, drawing the arm back a little and then extending the forearm he is able to deliver a blow. He has power over the trapezius, but less than on the right side, and its atrophy is as conspicuous as that of the extremities on the left side. It cannot be said that the wasting has advanced any since Igor. There is no paresis in the facial muscles or in the masseter. The left half of the lower lip is thicker than the right. Indeed the lower part of the face is fuller on the left than on the right (unaffected) side. This is said to be congenital and to have been observed in three generations of the patient's family. When the upper and lower rows of teeth meet, the space between the two lower middle incisors is a little to the left of the upper one. The left lower extremity is not worse than in the first period of my observation: indeed the patient thinks he has more strength in the calf muscles. He is not able to produce any visible movement at the ankle or in the toes when he is lying on his back with the lower limb extended; if, however, I pull the foot down plantarward and then have him exert himself to bring it dorsalward action may be distinctly observed in the anterior tibial muscle. This action may also be perceived when he attempts dorsal flexion of the foot while crossing the left leg over the right knee. Flexion of the knee is weakened, but extension is still quite powerful. a condition analogous to what has been described in regard to the elbow. When the patient draws the left thigh up to the trunk while he is recumbent, he has to hold the thigh with his hand to prevent it from falling outward.

No inequality has been observed in the action of the abdominal muscles.

There is no tendency to contractures in the affected limbs. 
Both knee-jerks are lively, the left distinctly exaggerated. Ankleclonus can generally be elicited without difficulty on the left side. The plantar reflexes could usually not be obtained with certainty. But recently Oppenheim's methcd gave a flexor response in the smaller toes of the right foot and a distinct extensor response in the big toe of the left foot. Of late neither cremaster nor abdominal reflex has been obtained. The disappearance of the $a b-$ dominal reflex may be explained by the flabbiness of the abdominal wall in consequence of the reduction of the paunch. The reflexes of the upper extremities contrast with those of the lower. They have not at any time been lively, some times they were rather hard to get at all. In February, 1903, it was noted that there was a distinct elbow-jerk on the left (the affected) side, while it could not be got with certainty on the right. A reflex could barely be excited by tapping the radius at its lower end, while it was plainly enongh to be produced on the sound side. All the affected muscles react in a normal manner to faradic and galvanic currents.

There is no disturbance of sensation of any kind anywhere. Pupils, optic discs, bladder are normal. There is no nystagmus.

The characteristics of this case are the weakness befalling successively the lower and upper extremities of one side, the flaccidity of the paralysis associated in the lower limb with increase of the tendon reflexes and abnormality of the plantar reflex while in the upper limb there is no exaggeration of the reflexes and the uniform wasting in the affected extremities without alteration of the behavior of the muscles to the electric currents.

This succession in the progress of the paralysis, the increase of the reflexes without contracture or spasm, and the uniform wasting without change in the electrical excitability of the muscles were all noted in the case of Mills, the publication of which called attention to this form of disease.

Patrick's ${ }^{2}$ description of the flaccidity in his patient, a girl 18 . years old, "as shown by the dangling arm, foot-drop and moderate steppage," tallies with what my patient presents. This condition differs conspicuously from the spasticity of the extremities mentioned in Spiller's ${ }^{3}$ report of a case under the title of "Progressive Ascending Unilateral Paralysis" it contrasts also with the rigid-

2Journ. of Nervous and Mental Drs., August, 1903.

- Ibid, Vol. 28 , p. 36 . 
ity mentioned by Potts" in his paper on "A Case of Lnilateral Ascending Paralysis, probably due to Multiple Sclerosis." 'there was no wasting and there was spasticity in the case reported by Mills and Spiller of a triplegia which had developed out of a hemiplegia which itself was considered to have borne the essential features of the disease under discussion. From their account I do not get the impression that we are dealing with quite adentical conditions.

The most extensive correspondence seens to me to exist between Patrick's case and mine. Besides the points of agreement already mentioned there is the inception of the disease at about the same period of life. But what distinguishes my patient from Patrick's and the others is the degree of paralysis to which the disease has progressed in the upper extremity and the feebleness of the reflexes in that part. This absence of exaggeration of the reflexes in the affected as well as in the sound upper extremity is a marked incongruity in the clinical picture.

The wasting which is common to Mills' first case, Patrick's, and mine is evidently an important characteristic of the disease.

It is not due to inactivity, for the lower limb is not inactive in any of these cases, and my patient exhibited the wasting in the upper extremity when he had still complete use of it.

On account of clinical differences one hesitates to apply the post mortem findings of Mills and Spiller to the present case. They found an uncomplicated degeneration of the direct and crossed pyramidal tracts. This degeneration would account for the increase of the reflexes in the lower extremities. According to Rothmann, who has made a critical survey of the facts bearing upon the subject, only the exaggeration of the reflexes, with clonus and the Babinski sign, may with certainty be considered as symptomatic of an affection of the motor tracts. If the degeneration of the pyramidal tracts sufficed to explain the spastic condition in the case of Mills and Spiller, something more, or less, would be required to explain the flaccidity in the other cases. Before, however, we attempt to refer the several symptoms to lesions of this or that structure we must confront the question whether we are dealing with a diffuse or a systemic or a focal disease. Potts saw such other symptoms associated with an ascend-

'Journal of Nervous and Mental Diseases, Oct., Igol.

' Ibid, July, rgo3. 
ing unilateral rigid paralysis as to lead him to the assumption of multiple sclerosis. No basis for such an assumption is given in this instance. Nor has anything developed during more than four years of observation to prove the existence of a focal cerebral lesion. The impression grows on me that there is a systemic disease in the spinal cord perhaps involving cells in the anterior horns as well as motor tracts yet different from the ordinary type of amyotrophic lateral sclerosis. 